\title{
LOWER LIMB KINEMATICS ANALYSIS DURING ROUNDHOUSE KICK AMONG NOVICES IN MUAY THAI
}

\author{
C. Chinnasee ${ }^{1, *}$, N. I. Mohamad ${ }^{2}$, A. M. Nadzalan ${ }^{2}$, A. H. A. Sazili ${ }^{2}$, W. Hemapandha ${ }^{1}$, L. \\ Pimjan $^{3}$, T. K. Azizuddin Khan ${ }^{2} \&$ K. Tan ${ }^{2}$ \\ ${ }^{1}$ Department of Sports Science, Faculty of Health and Sports Science, Thaksin University \\ Papayom, Phatthalung, Thailand \\ ${ }^{2}$ Faculty of Sports Science and Coaching, Universiti Pendidikan Sultan Idris, Tanjung Malim, \\ Perak, Malaysia \\ ${ }^{3}$ School of Liberal Arts, Walailak University, Tasala, Nakhon Si Thammarat, Thailand
}

Published online: 10 November 2017

\begin{abstract}
This study was conducted to examine the lower limb kinematics during roundhouse kick in MuayThai. Fifteen MuayThai novices (mean age $=21.52 \pm 1.09$ years old) with 2-3 months experiences in MuayThai training were recruited and were asked to perform roundhouse kick for each side of legs (dominant and non-dominant). Joint angles and velocity between the dominant and non-dominant lower limb were compared during both strikes. Dominant lower limb were shown to have greater hip flexion velocity, knee flexion velocity, ankle upward and lateral velocity compared to the non-dominant lower limb. Results demonstrated the asymmetries between dominant and non-dominant sides of lower limbs existed during roundhouse kick among novices in MuayThai.
\end{abstract}

Keywords: asymmetry, attacking strike, joint angle, velocity, novice.

Author Correspondence, e-mail: chamnan21@hotmail.com

doi: http://dx.doi.org/10.4314/jfas.v9i6s.73 


\section{INTRODUCTION}

MuayThai is a martial art and a method of self-defence that started in the ancient times as a way to protect self from the enemies [1]. As one of the most popular martial art sport in the world, a MuayThai match consisted of five rounds of fighting with three minutes per round and two minutes rest between rounds. Punches, elbow strikes, knee-strikes and kicks are the main attacking methods that can be executed to any part of the opponent's body.

Not many studies have been conducted on MuayThai. Researches in MuayThai has been conducted on the injury analysis [2-5], physiological responses [6, 7], biomechanics $[1,8,9]$, performance analysis $[10,11]$ and psychology $[12,13]$. Mohamad et al. [14] in their review addressed the needs of more researches to be conducted on MuayThai in order for the coaches, athletes and the team management to get more knowledge on the sports that will lead to better performance enhancement plan.

Among the field of research that will be very beneficial is the biomechanics. It is important to analyse the movement especially the techniques that are to be performed. Among those techniques that were allowed to be used in MuayThai, roundhouse kick was thought to be among the most used techniques among the MuayThai fighter. As in other martial arts, roundhouse kick also play a major role in MuayThai [1]. Consisted of four basic components; i) turning the hips, ii) pivoting the supporting foot, iii) swinging the arms, and iv) striking with the lower shin or instep [15], the roundhouse kick usually targeting three primary parts of the opponent's body which are the head, trunk and thighs. Great force produced during roundhouse kick will be advantages as this can cause opponent to be defeated.

Instead of the importance of the roundhouse kick, lack of studies has been conducted on the action in MuayThai. Thus, it is the objective of this study to examine the lower limb kinematics during roundhouse kick in MuayThai. The analysis will involve both dominant and non-dominant lower limb and comparison will be made between both sides of lower limb.

\section{METHODOLOGY}

\subsection{Participants}

15 male MuayThai beginners (mean age $=21.52 \pm 1.09$ years old) were recruited as study participants. Participants have less than 1 week experience in systematic MuayThai training. 
Participants had no medical problems and were screened prior to testing using PAR Q. Each participant had read and signed an informed consent prior to data collection. Participants were involved in a familiarization session to familiarize them with the technique execution. All information about the data collection procedure was informed during the familiarization session.

\subsection{Roundhouse Kick}

During the starting (ready) position, participants were asked to face an instructor that were holding a kicking target, with knees that were slightly bend, and the leg that was going to kick at that trial need to be in front of the other (Figure 1a). After receive the start instruction, participants take a step forward before execute the roundhouse kick to the kicking target as hard and as fast as they can (Figure 1e). Every participant performed three times of kicking execution for each leg.

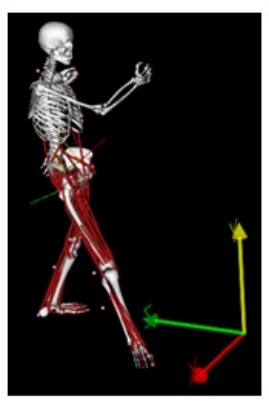

a

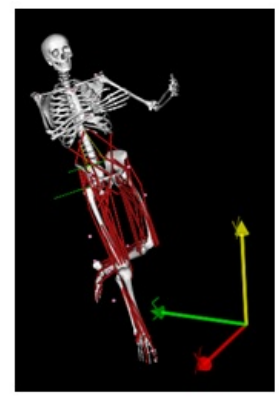

b

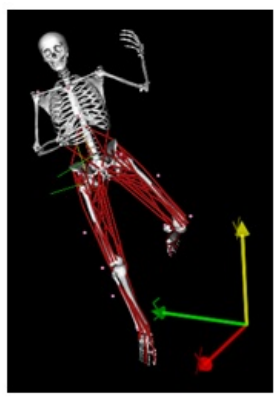

c

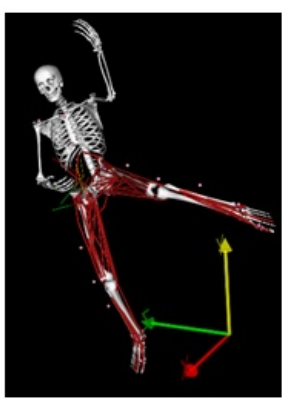

d

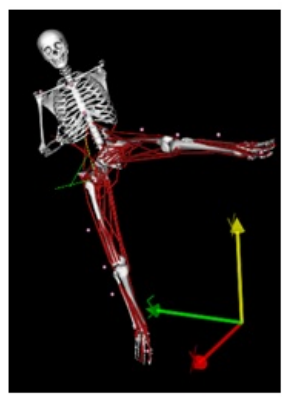

e

Fig.1.

\subsection{Kinematics Assessment}

Motion analysis system (Vicon T10s, Oxford Metrics, UK) was used to collect kinematics data, sampled at $100 \mathrm{~Hz}$. Based on the Plug-in-Gate Marker Set, 29 reflective markers were attached to participant body at the second metatarsal, lateral malleolus, calcaneus, lateral shank, lateral femoral epicondyle, lateral thigh and anterior superior iliac spine at both sides of body. The kicking target used was two hand-held kicking pads (MUAY THAI MT-KPC 1, Thailand). The kicking target was held by an assistant with hands at the body level of the 
subject. Analysis of data was conducted using Vicon Workstation software. The kinematic model of the lower body consisted of the shank, thigh and pelvis of the kicking leg. The angles of the hip, knee and ankle were examined.

\subsection{Statistical Analyses}

Descriptive data and mean score were measured using descriptive analysis. Repeated measure analysis of variances (MANOVA) was used to compare the differences of kinematics data between both dominant and non-dominant limbs. $\alpha$-level of $\mathrm{p} \leq 0.05$ was accepted as the statistical significance. All statistical analyses were conducted using SPSS version 23 (IBM, New York, USA).

\section{RESULTS}

Table 1 showed the physical characteristics of participants involved in this study.

Table 1. Physical characteristics of participants

\begin{tabular}{lllll}
\hline Age (years) & Body mass $(\mathrm{kg})$ & Height $(\mathrm{cm})$ & $\begin{array}{l}\text { Right Leg length } \\
(\mathrm{cm})\end{array}$ & $\begin{array}{l}\text { Left leg length } \\
(\mathrm{cm})\end{array}$ \\
\hline $21.52 \pm 68.82 \pm 4.53$ & $172.63 \pm 4.94$ & $87.45 \pm 5.78$ & $87.39 \pm 5.93$ \\
1.09 & & & & \\
\hline
\end{tabular}

Table 2 showed the mean angle of dominant and non-dominant knee and hip during the contact. No significant main effect were found for the knee flexion/extension, $F(1,15)=$ $0.340 ; \mathrm{p}>0.05, \mathrm{knee}$ internal/external rotation, $\mathrm{F}(1,14)=4.396 ; \mathrm{p}>0.05$, knee abduction/adduction, $F(1,14)=6.238 ; \mathrm{p}>0.05$. No significant main effect were also found for the hip flexion/extension, $F(1,14)=0.738 ; p>0.05$, hip internal/external rotation, $F(1,14)$ $=0.437 ; \mathrm{p}>0.05$, hip abduction/adduction, $\mathrm{F}(1,14)=3.762 ; \mathrm{p}>0.05$. 
Table 2. Knee joint angles

\begin{tabular}{lllll}
\hline Joints & Knee & $\begin{array}{l}\text { Dominant } \\
(\text { mean } \pm \mathrm{SD})\end{array}$ & $\begin{array}{l}\text { Non-dominant } \\
(\text { mean } \pm \mathrm{SD})\end{array}$ & p-value \\
\hline Knee & Flexion/extension $\left(^{\circ}\right)$ & $20.57 \pm 14.67$ & $18.14 \pm 10.37$ & .582 \\
& Internal/external rotation $\left(^{\circ}\right)$ & $2.37 \pm 4.38$ & $-2.38 \pm 3.28$ & .063 \\
& Abduction/adduction $\left(^{\circ}\right)$ & $-1.03 \pm 5.21$ & $5.31 \pm 12.39$ & .078 \\
\hline Hip & Flexion/extension $\left(^{\circ}\right)$ & $50.87 \pm 28.71$ & $49.72 \pm 27.30$ & .872 \\
& Internal/external rotation $\left(^{\circ}\right)$ & $-40.13 \pm 17.98$ & $-37.89 \pm 7.23$ & .529 \\
& Abduction/adduction $\left(^{\circ}\right)$ & $-10.72 \pm 21.23$ & $-20.54 \pm 11.63$ & .230 \\
\hline
\end{tabular}

Table 3 showed the mean angular velocity of knee and hip flexion for both dominant and non-dominant sites.Significant main effect were found for the knee flexion velocity, $F(1,14)=$ 9.763; $\mathrm{p}<0.05$, hip flexion velocity, $\mathrm{F}(1,14)=17.239 ; \mathrm{p}<0.01$.

Table 3. Angular velocity

\begin{tabular}{llll}
\hline & $\begin{array}{l}\text { Dominant } \\
(\text { mean } \pm \mathrm{SD})\end{array}$ & $\begin{array}{l}\text { Non-dominant } \\
(\text { mean } \pm \mathrm{SD})\end{array}$ & p-value \\
\hline Knee flexion $(\%)$ & $-959.46 \pm 302.13$ & $-626.40 \pm 324.83$ & .045 \\
Hip flexion $(\%)$ & $496.32 \pm 102.89$ & $302.52 \pm 104.93$ & .040 \\
\hline
\end{tabular}

Table 4 showed the mean of ankle forward, lateral and upward linear velocity for both dominant and non-dominant sites. No significant main effect were found for the ankle forward velocity, $F(1,14)=2.392 ; p>0.05$. Significant main effect were found for the ankle lateral velocity, $\mathrm{F}(1,14)=36.072 ; \mathrm{p}<0.001$, and the ankle upward velocity, $\mathrm{F}(1,9)=8.762 ; \mathrm{p}$ $<0.05$. 
Table 4. Ankle linear velocity

\begin{tabular}{llll}
\hline Ankle linear velocity & $\begin{array}{l}\text { Dominant } \\
(\text { mean } \pm \mathrm{SD})\end{array}$ & $\begin{array}{l}\text { Non-dominant } \\
(\text { mean } \pm \mathrm{SD})\end{array}$ & p-value \\
\hline Ankle forward $(\mathrm{m} / \mathrm{s})$ & $6.49 \pm 1.61$ & $5.96 \pm 0.86$ & .301 \\
Ankle lateral $(\mathrm{m} / \mathrm{s})$ & $7.92 \pm 1.48$ & $4.48 \pm 2.17$ & .000 \\
Ankle upward $(\mathrm{m} / \mathrm{s})$ & $5.38 \pm 0.48$ & $4.20 \pm 1.16$ & .015 \\
\hline
\end{tabular}

\section{DISCUSSIONS}

Lack of studies has been conducted on the biomechanical analysis of technique execution in MuayThai [16]. As roundhouse kick is regarded as one of the most important technique in Muay Thai, this study was conducted to determine and compare the kinematics of roundhouse kick between dominant and non-dominant lower limb.

In this study, dominant lower limb has been shown to produce significantly greater knee flexion velocity, hip flexion velocity, ankle lateral velocity, ankle upward velocity and ankle resultant velocity. No significant differences were found for any angles between dominant and non-dominant sites examined in this study.

The insignificant differences of the joint angle kinematics between dominant and non-dominant lower limb were consistent with several previous findings that had also found no significant differences of lower limb joint angles during several movement executions in martial art [8, 17-21].

Compared to some previous studies $[1,19,20,22]$, we can found that this current study has managed to find some contrast findings. In this study, dominant lower limb has been shown to produce significantly greater knee flexion velocity, hip flexion velocity, ankle lateral velocity, ankle upward velocity and ankle resultant velocity compared to non-dominant lower limb.

The findings of this current study was in line with several previous study that found the superiority of dominant lower limb compared to non-dominant. Trial (8) in his study among highly experienced martial artist found knee joint angular velocity was shown to be greater in the dominant site during clinching in Muay Thai although no significant differences were found in the hip and ankle joint angular velocity between the dominant and non-dominant leg. Besides that, study by Hsieh, Huang [21] on the roundhouse kick among elite taekwando 
athletes found that dominant leg produced significantly greater peak toe velocity, impact toe velocity and peak ankle linear velocity compared to the non-dominant limb.

However, the findings were also in contrast to some previous studies. Study by Falcó, Alvarez [22] found no differences in the reaction time, execution time and total response time between dominant and non-dominant lower limb during roundhouse kick among competitive taekwando athletes. Besides that, Tang, Chang [19]in their study among Taekwando national elite athletes found no differences of movement time, maximum velocity of toe, hip angular velocity, knee angular velocity, and ankle angular velocity during roundhouse kick between preferred and non-preferred leg. Harun and Xiong [20] found the national level Taekwando athletes display no significant differences of joint velocities during the turning kick when using both dominant and non-dominant legs.

Only one study has been conducted on the roundhouse kick in Muay Thai [1]. In his study, he found that final velocities of the ankle were similar at all high, medium and low target height. Positive relationship was found between the mean final velocity of the ankle and the mean peak force exerted by the roundhouse kick. A positive relationship also existed between the mean final velocity of the ankle and the mean impulse exerted by the roundhouse kick.

The difference of findings could be due to the different level of participants recruited. This study involved beginners that just learn the correct technique of roundhouse kick in Muay Thai. Participants in this study were still new and thus asymmetries existed during the skills execution between dominant and non-dominant leg.

\section{CONCLUSIONS}

This study provides an important understanding on the kinematics of one of the most popular techniques performed in MuayThai, the roundhouse kick in both the dominant and non-dominant lower limb. More biomechanics researches using advance technologies are warranted to be done on MuayThai technique as the speed of the martial art movements were very high make them virtually impossible to be analysed with the naked eye, and many traditional assumptions about optimal techniques may be incorrect. 


\section{ACKNOWLEDGEMENTS}

The authors would like to thank all the participants involved in this study.

\section{REFERENCES}

[1]. Sidthilaw, S., Kinetic and kinematic analysis of Thai boxing roundhouse kicks. 1996.

[2] Gartland, S., M. Malik, and M. Lovell, Injury and injury rates in Muay Thai kick boxing. British Journal of Sports Medicine, 2001. 35(5): p. 308-313.

[3] Gartland, S., M.H. Malik, and M. Lovell, A prospective study of injuries sustained during competitive Muay Thai kickboxing. Clinical Journal of Sport Medicine, 2005. 15(1): p. 34-36.

[4] Zazryn, T.R., C.F. Finch, and P. McCrory, A 16 year study of injuries to professional kickboxers in the state of Victoria, Australia. British Journal of Sports Medicine, 2003. 37(5): p. $448-451$.

[5] Vaseenon, T., et al., Foot and ankle problems in Muay Thai kickboxers. Journal of the Medical Association of Thailand= Chotmaihet thangphaet, 2015. 98(1): p. 65-70.

[6] Crisafulli, A., et al., Physiological responses and energy cost during a simulation of a Muay Thai boxing match. Applied Physiology, Nutrition, and Metabolism, 2009. 34(2): p. 143-150.

[7] Cappai, I., et al., Physiological responses and match analysis of Muay Thai fighting. International Journal of Performance Analysis in Sport, 2012. 12(3): p. 507-516.

[8] Trial, W., Kinematics comparison between dominant and non-dominant lower limbs in Thai Boxing. 2013.

[9] Trial, W. and T. Wu, A kinematic analysis of the Thai boxing clinch. Advances in Biomechanics and Applications, 2014. 1(1): p. 57-66.

[10]Ouergui, I., et al., Time-motion analysis of elite male kickboxing competition. The Journal of Strength \& Conditioning Research, 2014. 28(12): p. 3537-3543.

[11]Silva, J.J.R., et al., Time-motion analysis in Muay-Thai and kick-boxing amateur matches. 2011. 
[12]Myers, T.D. and N.J. Balmer, The impact of crowd noise on officiating in Muay Thai: achieving external validity in an experimental setting. Frontiers in Psychology, 2012. 3: p. 346.

[13]Ong, T.F. and W.I. bin Wan Ruzmin. Participation motivation in MuayThai among Malaysians. in Proceedings of the 2nd International Colloquium on Sports Science, Exercise, Engineering and Technology 2015 (ICoSSEET 2015). 2016. Springer.

[14] Mohamad, N.I., et al., Sport science based research on the sports of Muay Thai: A systematic review. Walailak Journal of Science and Technology (WJST), 2016. 14(8).

[15]Young, R.W., Muay Thai Roundhouse Kick. Black Belt. Vol. 29. 1991. 61-63.

[16]Mohamad, N.I., Sport Science Based Research on the Sports of Muay Thai: A Systematic Review. Walailak Journal of Science and Technology (WJST), 2016. 14(8).

[17]Andrzejewski, X. and L. Elbaum. Biomechanical analvsis of the front kick with the dominant and non-dominant limb in the shito-rvu style of karate. in ISBS-Conference Proceedings Archive. 2008.

[18]Falco, C., et al., Influence of the distance in a roundhouse kick's execution time and impact force in Taekwondo. Journal of Biomechanics, 2009. 42(3): p. 242-248.

[19]Tang, W., J. Chang, and Y. Nien, The kinematics characteristics of preferred and non-preferred roundhouse kick in elite Taekwondo athletes. Journal of Biomechanics, 2007. 40: p. S780.

[20]Harun, H. and S.J. Xiong, The symmetry in kinematics between the dominant and non-dominant legs in taekwondo turning kick. Unpublished. Degree thesis, UniversitiTeknologi Malaysia, Skudai, Malaysia, 2010.

[21]Hsieh, A., C.-F. Huang, and C.C. Huang. The biomechanical analysis of roundhouse kick in taekwondo. in ISBS-Conference Proceedings Archive. 2012.

[22]Falcó, C., et al. Kinetic and kinematic analysis of the dominant and non-dominant kicking leg in the taekwondo roundhouse kick. in ISBS-Conference Proceedings Archive. 2009.

\section{How to cite this article:}

Chinnasee C, Mohamad N. I., Nadzalan A. M, Sazili A. H. A, Hemapandha W, Pimjan L, Azizuddin Khan T. K. and Tan K. Lower Limb Kinematics Analysis during Roundhouse Kick among Novices in Muay Thai. J. Fundam. Appl. Sci., 2017, 9(6S), 1002-1010. 